JURISTAS PERUANOS,

\title{
José Gregorio Paz Soldán, Jurista y Diplomático
}

por el Dr. JOSE PAREJA PAZ SOLDAN.

(Apuntes de una biografía en preparación).

\section{LA FAMILIA PAZ SOLDAN - SU ORIGEN AREQUIPEÑO}

José Gregorio Paz Sodón nació en Arequipa, el 9 de mayo de 1808. Sus padres fueron don Manuel Paz Soldán, Ministro Tesorero de las Reales Cajas de esa ciudad, cargo que desempeñó durante 33 años hasta 1825, y doña Gregoria de Ureta y Peralta, y Araníbar. Don Manuel había emigrado de Panamá. Su Padre, don Manuel de Paz Soldón y Castro, natural de la Villa Carrión de los Condes de Castilla la Nueva y Capitón de los Ejércitos Españoles, había sido Capitớn del Batallón Fijo en aquella ciudad. Su esposa, doña Ana María de Paz Soldán, fue hija legítima de don Diego Paz Soldán, Fiscal de la Real Audiencia de Ponamá.

Don Manuel de Paz Soldán formó en Arequipa una extirpe de gran abolengo espiritual ya que ha dado brillantes e ilustres escritores y hombres de letras al Perú Republicano.

Don Manuel de Paz Soldán casó, en primeras nupcias, con doña María Josefa España y Escotena, de cuya matrimonio tuvo un hijo fallecido en tierna edad; y en segundas nupcias, con doña Gregoria de Ureta, de cuyo matrimonio nacieron los siguientes hijos:

doña Juana María, que casó con don Pablo Antonio Rada, abuela de los Rada y Gamio;

don Mariano Domingo, que acompañó al Libertador Simón Bolivar al Alto Perú, y reabrió la famosa Universidad de Chuquisaca, (célebre por sus doctores entre los cuales citaremos a Bernardo Monteagudo, el hombre de confianza de San Martín), radicándose allí y casándose con doña Victoria Valdez, tronco de una distinguida rama Paz Soldón de Bolivia;

don José Gregorio, nuestro biografiado;

don Pedro Silvero, financista, contraído y próspero agricultor, quién casó con doña Francisca Unánue, hija del sabio Hipólito Unónue, estirpe de la que descienden los Alayza Paz Soldán, los Rada y Paz Soldán y los 
Paz Soldán y Valleriestra. Pedro Silvero fue padre de don Pedro Paz Soldán $\mathrm{y}$ Unánue, ingenioso, poeta y notable humanista, conocido con el seudónimo de Juan de Arona; abuelo a su vez, entre otros, del Embajador Carlos Ortiz de Zevallos, Director del Archivo de nuestra Cancillería;

don Santiago José, naturalista, hombre misántropo, que se consagrá. al estudio de las Ciencias Naturales;

don Mateo Mauricio, sabio geógrafo y astrónomo, autor de la monumental Geografía del Perú;

doña Josefa Celedonia, que casó con el noble francés legitimista, natural de Nantes, don Manuel Rouad, padre de don Manuel Rouad y Paz Soldán, notable explorador que murió en las selvas amazónicas y abuelo de doña Luisa Paz Soldán Y Rouad de Moreyra Y Riglos, tronco de los Moreyra y Paz Soldán;

doña Francisca y doña Baltasara, muertas solteras:

don Niariano Feipe, polígrafo, historiador eminente y minucioso, autor del primer atlas geográfico del Perú, quien casó con doña Francisca Benavides y Payerle, y cuyo único hijo don Carlos Paz Soldán casó con doña Petronila Teresa Paz Soldón y Martínez, (hija de don José Gregorio Paz: Soldán) de cuyo hogar nació mi madre, doña Carmen Paz Soldán y Paz Soldán de Pareja y Llosa.

Don José Gregorio, después de oprender las primeras letras y algunos. rudimentos de matemáticas $\mathrm{Y}$ de gramática latina $\mathrm{Y}$ retórica, ingresó a los 14 años de edad, al famoso Seminario de San Jerónimo de Arequipa - S. Hyeronimus Arequipenses,- fundado por el venerable Obispo Chávez de La Rosa, notable y austero centro de formación intelectual Y patriótica, vivero de cultura, en que estudiaron, entre otros, Francisco Javier de Luna Pizarro,Benito Laso, Mariano Melgar, el Deán Valdivia, Nicolás de Piérola, Francisco Bolognesi, Francisco García Calderón y donde también cursaron sus estudios los cuatro Paz Soldán y Ureta; don José Gregorio, don Pedro, don Mateo y don Mariano Felipe.

En el Seminario, como se conoce por antonomasia el de San Jerónimo, don José G. aprenaió, Filosofía, Matemáticas, Teología y Derecho. Sus grandes maestros fueron Luna Pizarro y Andrés Martínez, que influyó tanto en su vocación jurídica. Al concluír sus estudios fue nombrado, inmediatamente, Profesor del claustro. Desempeñó la cótedra de Derecho Canónico durante 5 años. En 1832, publicó "Principios de Derecho Canónico", disciplina jurídica que dominó $\alpha$ fondo, por sus conocimientos jurídicos $\mathrm{y}$ de latín, y que mas tarde, recalcitrante realista, aprovecharía con ventaja, en los entredichos con la Curia Romana sobre Patronato y .Regalías, cuando fue Ministro de Relaciones Exteriores y Culto o en sus luminosos dictámenes como Fiscal de la Nación.

Al mismo tiempo que la docencia en San Jerónimo proseguía sus estudios jurídicos y profesionales en la Universidad del Gran Padre San Agustín, graduándose de Doctor en Teología y Jurisprudencia y recibiéndose de abogado, en agosto de 1831. Al poco tiempo era designado Relator de la Corte Superior; luego, Juez de Primera Instancia, en julio de 1833 siendo promovido en 1839 a la Fiscalía de la Corte Superior de Arequipa, a la tem- 
prana edad de 31 años, prometiendo pues una brillante y rápida carrera fudicial, magistradura a la que consagró su vida, muriendo con elejercicio de la Fiscalía de la Corte Suprema de la República en 1875 cargo que venía ejerciendo; con diversas vicisitudes desde 1851 .

\section{SU NOMBRAMIENTO AL MINISTERIO}

José Gregurio Paz Soldán fue Ministro de Relaciones Exteriores en tres oportunidades. La primera del 19 de mayo de 1845 al 29 de enero de 1848, que le sucedió don Matías León. Ia segunda vez de 9 de noviembre de 1853 al 25 de abril de 1854, durante la administración del General Echenique, reemplazóndolo el Dr. José Luis Gómez Sánchez. La tercera y última vez que desempeñó esa Cartera fue durante los pocos meses de la Presidencia del Mariscal San Román, ejerciendo las funciones de Presidente del Consejo de Ministros y Ministro de Relaciones Exteriores, de 27 de octubre de 1862 al 10 de abril de 1860, en que asumió el Ministerio el Dr. Juan Antonio Ribeyro.

Cuenta don Oscar Barrenechéa y Roygada, en su útil y documentado trabajo "Congresos y Conferencias Internacionales celebrados en Irma 1847-1894", que, en mayo de 1845, Pá́ Soldán se encontraba escondido en casa del Prefecto de Lima. Hay que anotar que había combatido y se había expresado en términos duros contra Castilla, en artículos en "El Comercjo" que firmaba con el seudónimo de Casandra y también, en peródicos eventuales. El Mariscal Castilla parece que conocía esta circunstancia del refugio y por ello, en una conversación con el Prefecto le dijo "Avísele al doctor Paz Soldán que tengo urgente necesidad de verle para un asunto de Estado". Como el Prefecto se hiciera aparentemente el extrañado y le preguntara "pero dónde puedo encontrar al doctor?" el astuto y cazurro Presidente le repuso "dígale Ud. no mas que venga". El hecho es que, al día siguiente, José Gregorio acudía a visitar al Presidente y éste, con la mayor naturalidad, sin referirse a la condición de enemigo y aun de refugiado político de su interlocutor, le dijo con toda llaneza: "Tengo que arreglar una enojosa cuestión con motivo de una reclamación inglesa y ningún otro sino Ud. puede solucionarla. Queda Ud. nombrado Ministro de Relaciones Exteriores". Paz Soldán tuvo que rendirse a las razones y a la generosidad de Castilla y aceptar la Cartera, que como anota el Embajador Barrenechea y Raygada en su obra mencionada, se le ofrecía de manera tan espontánea y honrosa.

Una de las características del Primer Gobierno de Castilla fué que buscó la colaboración de sus enemigos, cuando las exigencias del país lo requirieron, dentro de un amplio programa americanista y nacional. José Gregorio Paz Soldán era el talentoso Ministro que el genio de Castilla nece. sitaba para llevar a cabo su programa. Que importaba que el joven profesional estuviera al lado de Andrés Martínez y del grupo de Vivanco y que hubiese publicado en "El Comercio" las predicciones de Casandra con un claro sentido opositor. Lo que interesaba al caudillo peruano era el 
patriotismo y la capacidad técnica de ese candidato que venía de las filas opuestas. Y Castilla no se equivocó" (1).

\section{LA CUESTION INGLESA}

El agudo problema $\alpha$ que se refería el Presidente Castilla era la llamada Cuestión Inglesa. En agosto de 1844, fuerzas navales de la Gran Bretaña habían aprehendido, en la rada de Islay, a la escuadra peruana como represalia y desagravio, según alegaron las autoridades británicas, la detención del vapor de bandera inglesa "Perú", que intentaron realizar meses antes, las fuerzas revolucionarias del General Castilla, que combatían al Gobierno del Directorio presidido por el General Vivanco.

Consideró el comando de la escuadra inglesa, destacada en el Pacífico Sur, que la bandera de su país requería un desagravio y procedió, el 14 de agosto de 1844, a la detención y custodia de toda la escuadra peruanala que se había pronunciado por Castilla, y que se hallaba concentrada frente a Islay. Pocos días después, el $1^{\circ}$ de setiembre, el buque inglés Cormoran fué a hacer su aguada al Puerto de Arica, jurisdicción del Departamento de Moquegua; pero, por órdenes del Prefecto castillista, don José Félix Iguaín, se le negó todo auxilio y entonces el Carmoran bombardeó dicho Puerto. En el fondo de este asunto estaba invívita la parcialización del representante diplomático y de las autoridades navales inglesas a favor de Vivanco y su mal disimulada antipatía a Castilla.

La Cuestión Inglesa quedó solucionada con la llamada transacción de 30 de Mayo de 1845, negociada y concluída a los pocos días de asumir el Ministerio.

Al Gobierno de Castilla le urgía liberar a la escuadra peruana prisionera, afirmar la paz interna en el país, para iniciar la recontrucción del país y concluír con cualquier factor de inquietud. Era importante pues terminar con un pretexto o bandera para un movimiento revolucionario, haciendo cesar esa mal disimulada intervención inglesa. El Gobierno cedió pues "para evitar mayores males al país" (2).

Por ello en la llamada transacción, como expresamente se le denomina, a la que llegaron el Canciller Paz Soldán y el Encargado de Negocios de la Gran Bretaña se declaraba que se celebraba "bajo el imperio de las circunstancias" pero "las concesiones y la terminación de este negocio por la presente transacción no servirán de regla, ejemplo ni antecedente en otras posteriores que puedan ocurrir".

Según los términos de la transación, debía removerse al Coronel Arancibia del Gobierno de Arica y al General José Félix Iquaín de la Prefectura de Moquegua, dando el Gobierno de Lima su palabra de honor de no colocar al mencionado militar en ningún otro cargo político o militar. Ade-

(1) Víctor Andrés Belaúnde.- Discurso pronunciado en el Centenario del Congreso de Lima de 1847. En Mercurio Peruano Lima, 1948. Enero. No 250,

(2) Carlos Paz-Soldán.-Una Rectificación Histórica.-Lima, 1897. 
más el Encargado de Negocios de S.M. Británica aceptaba la satisfacción dada en cuanto al Coronel Artaza y agregaba que su Gobierno quedaba plenamente reparado por los agravios por los cuales se había quejado.

\section{LOS RESTOS DEL GENERAL LA MAR}

Una ley de la Convención Nacional de 1834 había dispuesto que el Gobierno del Perú verificase el tratado de los restos del ex-Presidente La Mar, que falleció en Cartago de Costa Rica, la que quizós le recordó su tierra natal por su relativa altura y sus añejas costumbres. Su vida allí había sido de recogimiento y de amargura, falleciendo el 12 de octubre de 1838 (1). La ley no se cumplió pero la Sra. Francisca Otoya había procedido por su cuenta, a trasladarlo al Perú. Otra ley de 16 de setiembre de 1845 invitaba al Gobierno a cumplir, sin demora, la ley de 1834.

Se procedió pues, a ordenar lo conveniente para honrarlos y darles sepultura en Lima, en un mausoleo levantado al efecto. El Gobierno del Ecuador, en cumplimiento de una resolución del Congreso Nacional, reclamó para sí esos restos, para trasladarlos a Guayaquil y envió con tal objeto a los Comisionados General de División Antonio Elizalde y al poeta José Joaquín de Olmedo. Estos enviaron a Paz Soldán una nota de fecha de 10 de febrero de 1846. Pero, como señala Juan de Arona en sus Páginas Diplomáticas, "en una hermosa $y$ elocuente nota negaba al Ecuador el derecho de repatriar esas cenizas", pues como señalaba en su Memoria, no se podía acceder "por razones de decoro nacional, de justicia y de respeto a las leyes del Congreso". En otra nota a los señores comisionados del Ecuador, de 20 de marzo de 1846, añadía que permitir la extradicción de esos restos, que se hallaban en playas peruanas, sería inferirle una segunda expatriación. "Por inmensa que sea la gratitud del pueblo ecuatoriano, el Perú posee este depósito inestimable, le ha debido al General La Mar días de gloria, puesto que peleó bravamente en Ayacucho en donde el Perú nació al mundo". Les agregaba que esas cenizas reposarán "en el suelo del Perú que tanto amó $y$ de cuyos hijos fue igualmente amado".

Convencido de nuestra razón, el Ecuador se hizo representar en las ceremonias de la exhumación de esos restos; "Este acto augusto, digno de un pueblo libre, ha sido el fallo tremendo de la nación contra las revoluciones, y el respeto que hemos tributado a la santidad de las leyes y de

(1) "Los restos de La Mar fueron exhumados de orden del Presidente Morazán qu॰ había recibido ese encargo del General Bermúdez en lima en 1841; pero una sublevación popular derrlbó a Morazán y quedaron ellos en poder de un oficial salvadoreño, siendo objeto de la codicia de otros interesados ya que estaban guardados en una una de oro. Gracias $a$ las gestiones de la señora Francisca Otoya, vecina de Paila y esposa de un alemán avecindado en Costa Rica, salieron de esa República en abril de 1844. Es posible que la señora Otoya los guardara tres años, pues al Cementerio de Lima no llegaron hasta el de 2 de marzo de 1847 para ser acariciados, sólo entonces, por la glorla sarcástica de los homenajes póstumos".

Basadre, Jorge. Historia de la República del Perú. Lima, 1949. Tomo I, pág. 119. 
las instituciones sobre la tumba del que fué Presidente legítimo del Perú", comentaba Paz Soldán en su Memoria de 1847.

\section{CUESTION DEL BERGANTIN "TRES AMIGOS"}

Según una de las cláusulas del Tratado celebrado entre el Gobierno de la Confederación Perú-Boliviana y el de S.M. Británica, de 5 de julio de 1837, el Perú se había comprometido a prohibir la introducción de esclavos en su territorio, Tratado, que posteriormente el Perú había desahuciado por considerarlo lesivo a los intereses nacionales. Sin embargo, el Cónsul General inglés, Mr. Wilson, había enviado una nota el 9 de setiembre de 1846 solicitando, en cumplimiento del artículo XIV de aquel Convenio, que se diesen las órdenes del caso para que no se permitiera el ingreso de los esclavos que transportaba a costas peruanas, el bergantín peruano "Tres Amigos". El Canciller Paz Soldán contestó que se negaba a entrar en negociaciones sobre este asunto por haber sido declarado nulo aquel tratado por nuestro país. En vista de esa declaración insistía el Cónsul que tenía instrucciones para sostener la validez del Tratado y que por lo tanto, zarparía al día siguiente del Callao un buque de guerra inglés con el objeto de interceptar al bergantín "Tres Amigos" e impedir el desembarco de esos esclavos. Basadre, en su magnifica Historia de la República, observa con agudeza, que "es curioso que Castilla resultara asumiendo una actitud favorable a la esclavitud en oposición a la que tomara año más tarde". Poco antes, el Canciller inglés Lord Palmerston, ruda y activamente, había advertido a nuestro Ministro en Londres, Iturregui, "que según su Gobierno en adelante como en lo pasado, las fuerzas navales británicas en el Pacífico serán enérgicamente empleadas en proteger $\alpha$ los súbditos ingleses y sus propiedades, en defensa de los intereses de este país, $y$ en mantener el honor de la Corona de S.M."

Paz Soldán no se amilanó, ofreciendo rechazar la fuerza con la fuerza. Protestó por la actitud ofensiva del Cónsul britónico y por el ultraje inferido al honor de la Nación peruana con la amenaza que se le hizo, haciendo caer la responsabilidad de cualquier acto de fuerza sobre el Cónsul y el Gobierno, "ofreciendo, también, hacer valer sus derechos de todos modos Y por todos los medios conocidos entre los pueblos civilizados". Agregaba: "el Gobierno del Perú no cederá, estando resuelto a todo; que si alguna vez y en momento menos felices (se refería a la Cuestión Inglesa) creyó prudente transigir, eran muy distintos el teatro y las circunstancias".

Finalmente la cordura y el buen sentido tornaron al Cónsul inglés que no se atrevió a cumplir sus amenazas, limitándose a protestar, nuevamente, por la introducción de ese grupo de esclavos, ofreciendo someter el asunto a la consideración de su Gobierno. 


\section{PRONTA ADMINISTRACION DE JUSTICIA}

En un expediente que tramitaba don Manuel Ortiz de Zevallos, Paz Soldán dictó la resolución supremá de 4 de agosto de 1846. Estimando que el expediente se había retardado por los artículos maliciosos que habia puesto la parte contraria "disponía que se devolviera" a la propia Corte Suprema, $\alpha$ fin de que, con la prontitud y exactitud que recomiendan las leyes $y$ que debe cuidar el Gobierno en uso de sus atribuciones, resuelva el recurso de nulidad "observando además el cupo de papel sellado que se venía usando".

La Corte Suprema se dirigió al Consejo de Estado. Estimaba que la resolución dictada por el Ministro Paz Soldán "invadía" las atribuciones del Poder Judicial saliéndose de los límites constitucionales y atacando su independencia. Paz Soldón a su vez, observó que la independencia del Poder Judicial no lo colocaba fuera del universo y libre de toda inspección humana, cuando la Constitución facultaba al Poder Ejecutivo para requerir la pronta y exacta administración de la justicia. No interfería en el Poder Judicial, sino mandaba simplemente, que la justicia se haga. Su función es aplicar la ley. Ingerirse sopre la facultad con que se dictó un decreto es apropiarse de facultades legislativas y salirse de la órbita de sus atribucionea específicas, usurpando las de otros Poderes.

\section{RECLAMACIONES DIPLOMATICAS}

Desde que el Penú se inició a la vida independiente se estableció, por Decreto de noviembre de 1821, la igualdad jurídica $y$ civil entro nacionales y extranjeros, gozando éstos igualmente de la protección del Gobiemo y de las leyes del Perú, pero estando, también, sujetos a las autoridades peruanas "perdiendo, decía el Decreto respectivo, la facultad de pedir la intervención de los comandantes de buques de guerra o de los cónsules, a no ser por una manifiesta infracción de sus derechos".

Los extranjeros residentes en el Perú, especialmente los pertenecientes a naciones europeas, tuvieron un complejo de superioridad y quisieron gozar en la práctica, de fueros privativos. Sus Agentes Diplomáticos y aún las propias Cancillerias extranjeras, ampararon constantemente, demandas carentes de razón y hasta trataron de reabrir procesos fenecidos, solicitando enormes cantidades al Erario en circunstancias, como alguién advirtió, en que "era muy vivo el entusiasmo de la injuria".

Las Naciones Americanas recién se organizaban. Las revoluciones eran frecuentes, la anarquía muy generalizada. Eran propicias las circunstancias que encontraban los extranjeros para asegurarse, prontamente, una holgada situación económica. Pero eran también notorios los riesgos derivados de nuestra inestabilidad política y el hecho de domiciliarse en nuestro país implicaba su aceptación. Muchos extranjeros fueron destacados elementos de progreso cívico, económico industrial. Pero no faltaron los que crecron 
- se encontraron con dificultades, asumiendo, entonces, una actitud incomprensiva y hostil, creyéndose autorizados para quebrantar las leyes a su antojo o para gozar de un régimen de excepción, amparados por sus Agentes Diplomáticos o Consulares, los cuales muchas veces planteaban al Gobierno sus reclamaciones en términos y maneras incompatibles con nuestra dignidad nacional y el respeto debido a nuestra soberanía. Las frecuentes conmociones internas y los daños y apropiaciones que originaban las revoluciones llevaron, $\alpha$ su vez, $\alpha$ los Gobiernos de las Potencias Europeas a tratar de intervenir, especialmente el de Inglaterra, para proteger a sus súbditos cualquiera que fuera la justicia que les asistiera. "El Gobierno Britónico ha creado entonces, un derecho público que aplica a los pueblos débiles que se llama Derecho de la fuerza y lo pone en ejercicio siempre que conviene a sus intereses" (Paz Soldán).

El Decreto Supremo de 17 de abril de 1846, que se conoce como "Declaración sobre Reclamaciones Diplomáticas", marca una etapa fundamental en nuestra historia diplomática. Indica al mismo tiempo un resurgimiento nacional $y$ un anticipo de la actitud de primacía $y$ de brillo que va $a$ tener la diplomacia peruana en estos años; expresa la decisión de que los problemas internacionales se ventilen en pie de absoluta igualdad y dentro de los cauces universales del Derecho Internacional; refleja que el Estado Peruano ya está adquiriendo su forma y relieva el sentido del honor y de la dignidad que serán características del Gobierno de Castilla.

En los considerandos de dicho Decreto se expresa que muchos de los reclamos formulados por los Agentes de los Gobiernos extranjeros a favor de sus súbditos han sido admitidos o discutidos, sin que siquiera hubiera precedido, por parte de los interesados, gestión alguna ante los Tribunales o ante las autoridades encargadas de examinar los hechos, proce. dimiento que es contrario al Derecho Internacional. En virtud de esos antecedentes el Gobierno del Perú declara que no admitirá en lo sucesivo "reclamación diplomática ni la interposición o personería de los agentes públicos de otras naciones en favor de sus súbditos, sino en el caso que éstos hubieran ocurrido a los Tribunales, Juzgados y demás autoridades de la República a solicitar justicia en defensa de su derecho y constataran que se les ha denegado o retardado". (Art. 1). Las podrá admitir en aquellos casos especiales en que las hace admisibles el Derecho de Gentes y que por su naturaleza, deba resolverlas el Gobierno (Ārt. 2). Y siendo la administración de la justicia independiente en el Perú y no siendo posible abrir procesos fenecidos, los fallos expedidos por los tribunales $y$ juzgados sobre reclamos interpuestos por súbditos de otros Estados, el Gobierno los respetará y hará cumplir como cosa juzgada, no pudiendo en ningún caso actuar contra lo que por ellos se resolviera (Art. 3.)

\section{CRITERIO COLONIAL DEL SIGLO XIX}

Como ya lo hemos expresado en otro trabajo (1) "estamos viviendo el final del colonialismo, la gran aventura que comenzó en el siglo XVI y cul-

"(1) Las Naciones Unidas - Revista "Derecho" N9 XVII - 1958. 
minó en el siglo XIX". En esa centuria llegó al cenit de su poder y de su éxito, la aventura colonial, culminando el reparto del mundo no europeo por las Grandes Potencias. América Latina, que había alcanzado su indepen$\mathrm{ci}$, en los primeros 25 años de ese siglo, fué salvada de cualquier veleidad. colonialista o de reconquista por nuestra conciencia de Patria, unida a una sincera y profunda convicción de libertad, a la posición anticolonial de los Estados Undos y a la Doctrina de Monroe, aunque no dejamos de ser objetos de amenazas y de expediciones de reconquista, las que felizmente fracasaron.

Pero áquella es la época de los grandes imperios coloniales de Inglaterra y de Francia y en menor escala o llegados más tarde, del Portugal, Italia, Holanda, Bélgica y el Japón.

Pero ese período de apogeo de la mentalidad colonial fue muy grave para nosotros. Las metrópolis trataban a sus colonias como simples factorías productoras o depósitos para las materias primas que necesitaban y como mercados exclusivos para sus manufacturas. Se creó una psicolo. gía colonial; arrogante, imperativa y prepotente que también quisieron implantar en sus relaciones con América Latina. Los súbditos de esos países tenían la razón siempre en sus pleitos o querellas contra los nacionales o en sus quejas y agravios contra el Estado. El Agente Diplomático - Consular, sin haber agotado la vía judicial o administrativa, en esas reclamaciones privadas de sus nacionales, dirigía al Gobierno conminatoriamente, para una solución pronta y a su entera satisfacción. $Y$ a veces no faltaba la amenaza velada o explícita de una represalia o de un desembarco de sus marinerías.

Entonces y después, casi hasta 1920, los grandes consorcios internacioles, industriales o explotadores, trataban de obtener del país en que trabajaban las móximas utilidades en el menor tiempo posible, sin interesarse por el trabajador nativo, sin vincularse y servir al mismo tiempo a la nación donde actuaban, sin preocuparse por el futuro de la misma $y$ por la suerte de sus habitantes, mentalidad colonial que, por fortuna, ha desaparecido en la mayoría de los nuevos dirigentes industriales de las grandes compañías extranjeras, y que ha sido reemplazada, oportunamente, por una cinsera voluntad de servicio, de promoción $Y$ de respeto por el país donde trabajan.

La liquidación definitiva del colonialismo político y la evolución sagaz del colonialismo económico conmenzaron al finalizar la Primera Guerra Mundial, con la independecia de casi todas las grandes colonias, el advenimiento al estado independiente de 40 nuevas naciones, algunas tan importantes como la India, con una población en conjunto de mil millones de almas, facilitada además por la intensificación del nacionalismo, el debilitamiento de las grandes potençias europeas que gobernaron en el mundo en el siglo XIX, el desplazamiento del poder militar hacia las super-Potencias, más industrializadas, que poseen las armas nucleares y atómicas y que pueden lanzar satélites al espacio como Estados Unidos y Rusia y finalmente, la difusión de un sentimiento generalizado de justicia social.

Dentro de esa realidad colonialista del siglo XIX y de la prepotencia de los representantes diplomáticos y consulares europeos en su trato con. 
los Gobiernos latinoamericanos es que se debe ubicar sus reclamaciones diplomáticas. Por lo cual la dignidad, firmeza y vigor jurídico de la tesis y defensa peruanas, hechas en el siglo pasado por el Canciller Paz Soldán, revisten mayor categoría y mérito.

\section{RESERVA DE LOS GOBIERNOS AL DECRETO DE 1846}

En su nota de 15 de abril de 1846, en el asunto Norris, expresaba el Canciller Paz Soldán que la intervención de agentes diplomáticos en los casos particulares de los súbditos extranjeros haría que éstos gozaran en sus asunfos privados en sus demandas $y$ en sus querellas, de derechos o privilegios que no gozan los ciudadanos del Perú, convirtiendo un asunto privado en internacional, prescindiendo muchas veces de justificar los hechos, y que su simple afirmación, repetida por el órgano respetable de un Ministerio, se convertiría en prueba, trastornando la justicia. En el Perú todas las autoridades son responsables conforme a la Constitución. Citaba a conocidos internacionalistas y el Tratado de Utretch para demostrar que la roclamación por la vía diplomátiça sólo procede si ha habido denegación o retardo en su aplicación. Fuera de esos casos no procede, pués, una reclamación directa la que, además, convierte al Gobierno en demandado y al Agente Diplomático en demandante. Los hechos y las pruebas deben alegarse antes los jueces. El Gobierno tampoco puede derogar los fallos de los tribunales y cuando la Cancillería manifiesta que no puede hacer una $\cos \alpha$, a nadie ofende ni daña; porque ninguno puede ser requerido a hacer más de aquello para lo cual está autorizado. "La prudencia aconseja, de acuerdo con la justicia, que a nadie se le obligue a que haga lo que no puede; $a$ que conceda lo que no debe; $\circ \alpha$ que intervenga en casos para los que no tiene poder".

Dorado observaba, refiriéndose al Decreto de abril de 1846, que las protestas de algunos agentes diplomáticos acreditados en Lima, estaban fundadas en el concepto que se negaba por el Gobierno Peruano toda partipicación de los Ministros Diplomáticos en los negocios que tuvieran interés los súbditos de sus respectivas naciones. Razonaban que antes del juicio no se les permitía intervenir porque deberían ocurrir primero a los tribunales; ni después, porque ya existía una sentencia que debería respetarse como cosa juzgada.

En su nota al Encargado de Negocios de Brasil (12 de mayo de 1846) aclaraba el Canciller el objetivo del Decreto. "No era propósito expedir órdenes $\alpha$ los agentes diplomáticos ni circunscribirlos en sus funciones sino simplemente lo que el Gobierno puede y lo que no puede según sus facultades constitucionales y el Derecho de Gentes y que se arreglaría en los casos que ocurran en lo sucesivo. "El rechazo que hace el representante del Brasil no afecta la conducta del Gobierno Peruano en una declaración que 
es una enunciación sencilla de verdades y máximas admitidas en todas partes" (1).

Dorado comenta que aunque los Gobiernos de Francia y de Estados Unidos hicieron reserva de su protesta al acusar recibo de la Declaración y comunicar que la habían trasmitido a sus respectivos Gobiernos, es dable presumir que quedaron convencidos de la justicia de la disposición peruana y que se conformaba con los principios del Derecho de Gentes, pues de lo contrario, habrían insistido, cursando nuevas instrucciones a sus agentes para que reclamasen con más fuerza con el objeto de lograr su renovacin.

Acusando recibo a una nota del Encargado de Negocios de Francia en que le formulaba reservas al Decreto, Paz Soldán señalaba, en su comunicación de 18 de noviembre de 1846, que "el Gobierno Peruano no puede adoptar como regla de conducta, las opiniones de ningún otro, por ilustradas que sean, si no estón conformes con las reglas del Derecho de Gentes. No es tampoco una reglamentación. Una Declaráción no envuelve la idea de reglamentar, pues solo contiene la manifestación que hace un Gobierno de su modo de pensar o de la conducta que se propone observar sobre una materia".

\section{PAZ SOLDAN RENUNCIA ALTIVAMENTE LA CANCILLERIA EN 1853}

El Encargado de Negocios de Francia, señor de Ratti-Menton, promovió una reclamación para el pago de una fuerte indemnización en dinero por alegados perjuicios, sufridos por determinados súbditos franceses, reclamación que carecía de base suficiente.

Paz Soldán preparaó una nota altiva y enérgica: "El Gobierno del Perú no reconoce ni reconocerá jamás el derecho de los Representantes de otros Gobiernos de arrogarse la facultad de imponerle el deber de pagar por satisfacciones, cuotas o multas pecuniarias. Si los extranjeros son damnificados debe repararse el daño, previo conocimiento del asunto y justificados que sean los puntos de la demanda. El Perú, como Estado soberano e independiente, tiene tanto derecho como el más poderoso, para ser considerado y respetado. Cederá a la fuerza pero no por eso reconocerá esos derechos ni obligaciones sino los que nazcan de los principios inmutables de la justicia".

Como la nota proyectada ni la sustitutoria que se remitió, fueran del agrado del Presidente Echenique, éste le decía en una carta Paz Soldán,

(1) "Estos incidentes ruidosos, en los que el Perú estuvo defendido con tanta justicia como habilidad... Es de advertir que también antes éramos a la vez que una Nación débil una Nación pobre y la codicia extraña, mal que a su pesar. se veía obligada a medir sus exigencias por la penuria de nuestro tesoro".

La condición jurídica de los extranjeros en el Perú por Félix Cipriano C. Zegarra. Sum. tiago, 1872 . 
en la" que "se trataba su miedo y su furor": "Hoy nos tirarán de cañonazos o nos humillarán y nosotros no habremos salvado el honor diciendo verdades y abriendo los ojos a la opinión pública". Paz Soldán, desde su hacienda de San Isidro, enviaba su renuncia de Ministro, el 20 de abril de 1854, la que fué aceptada ese mismo día, renuncia en la que expresaba: "Nos tirarón de cañonazos, que lo dudo, y harán más, porque así lo han resuelto, no porque Ud. ni yo les demos motivos. Cualquier contestación sería lo mismo. Si la mía le parece mala, puede usted mandarla retirar; yo seré el único que sufra y Ud. tomará el mejor camino. En circunstancias tales se sacrifica un Ministro y se salva el país; esto me basta para vindicarme ante Ud. En asunto tan grave solo me queda un partido $y$ es dejar el puesto, por lo que mando mi renuncia". Sálvese ella (su Administración) y el país Y el Ministro se ofrece como víctima".

Y como Echenique le reprochase que trente al ultimatum del Ministro francés y la amenaza de sus cañones, lo único que atinaba su Canciller era renunciar, Paz Soldán aclaraba: "Usted oyó ayer mis opiniones resueltas $\mathrm{y}$ vigorosas por sostener nuestros derechos y me dijo usted que serían buenas para las épocas normales. Ni la política interior ni los cañones franceses me hacen dejar el Ministerio, sino la falta de confianza de usted y la desaprobación de mi conducta tan ásperamente manifestada en su carta de hoy" (1).

Es evidente, dentro de la recta doctrina constitucional, que cuando existe un desacuerdo fundamental entre el Presidente de la República y un Ministro, la única alternativa es la renuncia del Ministro. Este es responsable por los actos de su Portafolio. "Los Ministros son responsables de los actos del Presidente que autoricen con sus firmas contra la Constitución y las leyes, pudiendo hacerse efectiva esta responsabilidad durante

(1) "El débil $\mathrm{y}$ asustadizo Jefe de la Nación (Echenique) temeroso de perder la escuadra, quiso cederlo todo, hasta el honor nacional, con tal de sostenerse en el puasto, pero se hallaba de por medio el campeón ilustre de la Nación (Paz Soldán), el delensor de sus prerrogativas, aquél que en 1845 había conseguido que el Gabinete de Washington retirara a su Ministro para satisfacernos; el mismo que en 1845 sostuvo el derecho del Perú para arreglar su navegación fluvial y que acababa de conseguir que uno de los Ministros Pleni. potenciarios do una nación fuerte, fuera reprendido por su Gabinete por haber querido sostener privilegios contrarios $\alpha$ los principios internacionales; ese coloso diplomático no quiso ceder a las exigencias del Ministro francés; declaró ante-el Consejo de Ministros $y$ en presencia del Contralmirante peruano que era preciso sostener con giloria, luchando contra la escuadra francesa en defensa del honor nacional; y que en caso de desgracia, mas glorioso sería ceder ante el poder de Napoleón que ante los caprichos de su Ministro en Lima. Su voz no tuvo eco; fue sofocada por el miedo del Jefe del Estado y por sus débiles Ministros. En tal alternativa no tuvo el Ministro Paz Soldán otro medio que el de renunciar el Ministerio... El doctor Paz Soldán nunca se mostró más hombre de Estado que después de su último Miniqterio".

Retrạto político del doctor Paz Soldán publicado el año 1864 Y reproducido por "E Comercio". el 20 de diclembro de 1875.

Las cartas cambiadas entre Echenique y Paz Soldán, sobre su salida del Ministerio están publicadas en "Mi Defensa", Pág. 67 y ss. 
su cargo" señalaba la Constitución de Huancayo de 1839 (art. 95), vigente cuando Paz Soldán desempeñaba la Cancillería, en 1853. La actual de 1933 agrega que no solo son responsables por sus propios actos y por los actos presidenciales que refrenden sino, por los infractorios y delictuosos de la Constitución y de las leyes o que se acuerden en Consejo de Ministros, aunque salven su voto, a no ser que renuncien inmediatamente. (Art. 179). A su vez el Presidente de la República no podía ni puede realizar actos de gobierno sin la refrendación ministerial.

Dentro de estas consideraciones y propiciando Paz Soldán una politica enérgica y fuerte frente a los desplantes del Representante francés; y el Presidente Echenique, una política contemporizadora, que su Ministro consideraba ofensiva para nuestra dignidad nacional, no quedaba a Paz Soldán otro camino que irse. Y cumplió su deber sin titubear y sin ocultarlo.

\section{MATRIMONIO Y PROPIEDAD DE LOS EXTRANJEROS}

Una circular de 31 de julio de 1840 había establecido trabas para el matrimonio de los extranjeros y para la adquisición de propiedad, determinadas por el temor a represalias o por demandas excesivas de esos extranjeros, amparados por sus representantes diplomáticos y consulares. Pero, considerando el Gobierno de Castilla superadas esas circunstoncias, expidió el Decreto de 23 de Agosto de 1845, por el que se permitió a los extranjeros casarse en el Perú y adquirir propiedades sin quedar nacionalizados. Se establecía eso sí, que todo juicio sobre propiedad situada en la república, quedaba sujeta exclusivamente a la jurisdicción nacional. Ese Decreto, señala Paz Soldán en su Memoria, fué acogido por el Cuerpo Diplomático del modo más favorable y sus resultados fueron muy ventajosos.

\section{LA LIBRE NAVEGACION DEL AMAZONAS Y LOS ESTADOS UNIDOS}

Al final de 1853, el Encargado de Negocios de Estados Unidos, J. Randolp Clay, plantearía al Canciller Paz Soldón la cuestión relativa a que habiéndose abierto para los buques del Brasil, la navegación del curso peruano de los ríos Amazonas y Huallaga hasta Yurimaguas, debía hacerse extensiva esa concesión a los buques y comerciantes norteamericanos, conforme a las estipulaciones del Tratado vigente entre ambos países, cslebrado en Lima el 28 de Julio de 1851, y particularmente lo señalado en sus artículos $2^{\circ}, 3^{\circ}$ y $10^{\circ}$. Con este motivo se cursó una interesante correspondencia. Mr. Clay envió dos extensas notas, de fecha 31 de diciembre de 1853 y de 4 de febrero de 1854. Paz Soldán replicó con otras dos, no menos extensas y de gran rigor jurídico, de fecha 16 de enero y de 28 de febrero de 1854, respectivamente.

Paz Soldán alegó en sus exposiciones que los buques brasileros navegaban en el sector peruano del Amazonas en virtud de la mutua y recíproca concesión, convenida en la Convención Fluvial de 1851 para los barcos y comerciantes de ambos países. Pero el Tratado con Estados Unidos sólo se 
refería a las costas, bañadas por mares, y no al interior de los ríos, cuyos mórgenes son riberas. A los súbditos y barcos brasileros se les permitía la libre navegación en sus níos interiores (amazónicos) en vía de la reciprocidad lo que no ofrecía ni podía ofrecer los Estados Unidos por no ser ribereño del Amazonas. Como no podía pues ofrecer dicha reciprocidad, tampoco. podía exigirla.

"Los ciudadanos y buques peruanos, agregaba el Canciller Peruano, tienen el derecho de navegar en el Ámazonas porque el Perú como Estado ribereño, participa de él mancomunadamente, con todos los Estados ribereños y porque las aguas de sus ríos contribuyen a formar el caudal de aquél. Por lo mismo, siendo el Perú uno de los socios y condóminos en los goces de la navegación, no puede trasmitir por si solo, derechos absolutos que él sólo no tiene. Un socio no dispone por su voluntad de intereses comunes cunque los goce en toda la extensión que corresponde a la sociedad entera... La navegación fluvial, perteneciente a diversos condóminos, es una servidumbre internacional, emanada del señorío que cada uno tiene en su respectivo territorio $\mathrm{y}$ de la situación que ocupa con relación a las aguas territoriales; tal servidumbre que es activa $y$ pasiva, al mismo tiempo, entre los condóminos que la gozan pero también la sufren, no puede trasmitirse $\alpha$ un tercero por la exclusiva voluntad de un partícipe" (1).

Además señalaba que lo que se pacta para la navegación maritima no puede extenderse a la fluvial, pues para la última es necesario celebrar tratados especiales. Por otra parte ni el Amazonas ni sus tributarios, pertenecientes al Perú, han estado abiertos al comercio extranjero. El Tratado con el Brasil, lejos de abrirlos, ha declarado y reconocido el principio de. que su naregación debe pertenecer exclusivamente a los Estados ribereños.

Observaba, finalmente, que en "el conflicto en los ríos interiores de un país -cuya navegación pertenece exclusivamente a uno o varios páses, la concesión de privilegios y el establecimiento de sociedades no se puede exigir como la emanación de tratados generales sino en el caso de que especialmente y de una manera clara, se haya estipulado, no bastando para obtenerlas, conjeturas o interpretaciones".

\section{LA LIBRE NAVEGACION DEL AMAZONAS}

La libre navegación del río Amazonas $y$ sus principales tributarios solo quedaría abierta a los pabellones de todos los Estados, años más tarde. Un Decreto brasilero, de 7 de diciembre de 1866, la declaraba abierta a partir del 7 de noviembre de 1867, a los buques mercantes de todas las banderas. Otro Decreto peruano, de 17 de diciembre de 1868, proclamó "abierta la navogación de todos los ríos de la República a los buques mercantes, cualquiera que fuera su nacionalidad". Con razón señala Ulloa -en su magnífico

(1) Véase Aicardo Aranda - Coleccióx de los Tratados del Perú. Tomo VII. Págs. 125 
libro Posición Intemacional del Perú- que "la completa libertad de navegación en el Amazonas no quedó pues establecida sino a partir de 1868". Agrega que los Estados Unidos habían reclamado anteriormente esa facilidad, amparándose en el Tratado Torrico-Clay de 1850 y que no puede negarse, "la influencia de los Estados Unidos en la libertad de navegación. en el Amazonas. Como esta influencia se ejerció principalmente sobre el Brasil y correspondía a las más claras conveniencias políticas y comerciales del Perú, parece evidente que nos fué provechosa".

La doctrina de la libre navegación de los ríos internacionales ha sido reciente. Comenzó a esbozarse solo a principios del siglo XIX y se afimó en el transcurso de esa centuria, en función de las grandes vías fluviales europeas. Se concretó, definitivamente, en el Pacto de la Liga de las Naciones de 1919 y en el Estatuto relativo al régimen de las vías navegables de interés internacional, suscrito en Barcelona, el 20 de abril de 1921.

El Perú, había sacrificado en la Convención Fluvial de 1851, espectativas territoriales muy apreciables en su disputa de límites con el Brasil, territorio que teóricamente nos reconocía el Tratado de San Ildefonso de 1777. para lograr la libre navegación del Amazonas y que ese Tratado otorgaba al Brasil con el carácter de exclusivo. El Penú no podía ceder a los Estados Unidos, un derecho que había obtenido a un precio tan elevado, y en virtud de una aplicación por analogía de dudoso fundamento. El Derecho Internacional de entonces no había llegado aun a aceptar la libre navegación de las vías fluviales internacionales. La negativa de Paz Soldón estaba cargada de razón; se basaba en el Derecho de Gentes entonces operante, y era de estricta lógica jurídica (1). La libre e irrestricta navegación del. Amazonas solo se haría realidad 15 años más tarde, en 1868.

(i) Con los Representantes de la. Gran Bretaña y de los EE. UU., sostuve una delicada discusión sobre la navegación del Río Amazonas, no defendiendo los principios de una política antileberal $Y$ restrictiva sino nuestros verdaderos derechos y la santidad de los Tratados con el Brasil".

J. G. Paz Soldán. Mi Dofonsáa. Pág. 8. 